\title{
Ocorrência de microrganismos indicadores em leite UHT ("ultra-high-temperature") integral
}

\author{
Occurrence of indicators microorganisms in integral UHT \\ ("ultra-high-temperature) milk
}

Naiá Carla Marchi de Rezende, ${ }^{*}$ Oswaldo Durival Rossi Júnior, ${ }^{\star \star}$ Antonio Nader Filho, ${ }^{\star \star}$ Luiz Augusto de Amaral**

\begin{abstract}
Resumo
Um total de 120 amostras de leite UHT ("ultra-high-temperature") de quatro diferentes marcas comerciais, adquiridas na região de Ribeirão Preto-SP, foram analisadas para a presença de microrganismos aeróbios mesófilos, termófilos e do grupo dos coliformes. A positividade para microrganismos indicadores aeróbios ou facultativos mesófilos e termófilos viáveis foi de $53,33 \%$ e de $44,17 \%$, respectivamente. Não foram encontradas amostras positivas na determinação de coliformes. A alta população de microrganismos indicadores mesófilos e termófilos encontrados em várias amostras analisadas indica a necessidade de melhorias nas condições higiênico-sanitárias adotadas no processo de obtenção do leite UHT, no sentido de minimizär as contaminações encontradas.
\end{abstract}

Palavras-chave: Leite UHT; microrganismos indicadores; microrganismos aeróbios mesófilos; microrganismos aeróbios termófilos.

\begin{abstract}
A total of 120 UHT (ultra-high-temperature) milk samples of 4 different commercial brands, purchased from Ribeirão Preto-SP region, were examined for the presence of mesophilic, thermophilic and coliforms group microorganisms. Mesophilic and thermophilic aerobic or facultative microorganisms occurred in $53,33 \%$ and $44,17 \%$ samples, respectively. Coliforms group wasn't present in any UHT milk samples examined. The high count of mesophilic and thermophilic aerobic or facultative microorganisms presents in a lot of analysed samples shows the necessity of improvements in hygienic and sanitary quality adopt in UHT milk process obtainment to minimize the contamination.
\end{abstract}

Keywords: microorganisms; milk; UHT.

\section{Introdução}

As toxinfecções de origem alimentar podem ser definidas como doenças que ocorrem em conseqüência da ingestão de alimentos contaminados por alguns microrganismos patogênicos ou por suas toxinas. Estudos demonstram que são responsáveis pela contaminação dos alimentos e conseqüente desencadeamento de surtos: a manipulação inadequada de alimentos, incluindo a falta de higiene durante a sua obtenção, e o seu processamento, o acondicionamento e a conservação inadequados de alimentos prontos ou semiprontos e o processamento térmico insuficiente desses produtos (Becker et al., 1994).

Da grande variedade de alimentos disponíveis à população para consumo, o leite destaca-se pela sua rica constituição, sendo inclusive usado, em muitos casos, como a única fonte de alimento para os recém-nascidos. Dessa forma, esperase que o leite consumido pela população apresente boas características microbiológicas, o que pode ser conseguido através de rigorosas medidas higiênico-sanitárias aplicadas desde a sua obtenção até o momento do seu consumo.
$\mathrm{Na}$ avaliação da qualidade do leite, utiliza-se de determinações microbiológicas, particularmente de alguns grupos de microrganismos, tendo em vista a impossibilidade de se pesquisar todos os microrganismos que podem estar presentes, devido ao alto custo e à necessidade de técnicas sofisticadas, que envolvem tempo excessivo. Os microrganismos utilizados para esse fim são ditos indicadores.

Para que um microrganismo indicador represente de forma segura as condições microbiológicas do leite e, conseqüentemente, seu padrão higiênico-sanitário, ele deve possuir algumas propriedades que facilitem o seu isolamento do produto em estudo e que assegurem as reais características microbiológicas do alimento.

Os grupos de indicadores freqüentemente pesquisados no leite são os microrganismos aeróbios ou facultativos, que envolvem os mesófilos, os termófilos e os psicrotróficos, e os indicadores de contaminação fecal, que envolvem os coliformes totais e os coliformes fecais.

Os microrganismos mesófilos, que têm temperatura ótima de crescimento ao redor de $35^{\circ} \mathrm{C}$ e os microrganismos

\footnotetext{
* Mestre em Medicina Veterinária pelo Curso de Pós-Graduação em Medicina Veterinária Preventiva da FCAVJ/UNESP.

* Departamento de Medicina Veterinária Preventiva e Reprodução Animal da FCAVJ/UNESP - Rod. Carlos Tonnani, Km 5, 14870-000, Jaboticabal, SP.
} 
termófilos, cuja temperatura ótima de crescimento está perto dos $55^{\circ} \mathrm{C}$, indicam o grau de higiene com que o produto foi obtido e/ou processado. Por outro lado, os indicadores de contaminação fecal indicam os aspectos sanitários de um alimento. A maioria dos patogênicos para o homem são de origem fecal (Hitchins et al., 1992).

Os coliformes totais são representados pela Escherichia coli, Enterobacter aerogenes, Citrobacter freundii, Citrobacter intermedium e Klebsiella. Os coliformes fecais são, na sua maioria, representados pela Escherichia coli (Hitchins et al., 1992).

Bodyfelt (1980) e Collins (1981) mostraram ser as vacas leiteiras, as máquinas que processam o leite, as tubulações, os recipientes, os tanques de estocagem e as válvulas de saída dos tanques, as principais fontes de contaminação do leite. Tudo precisa estar muito bem limpo e sanitizado para minimizar a contaminação do alimento.

Assim, o objetivo deste trabalho é quantificar a possível presença de microrganismos aeróbios mesófilos e termófilos e do grupo dos coliformes em amostras de leite UHT adquiridas no comércio da região de Ribeirão Preto (SP).

\section{Material e métodos}

Foram analisadas 120 amostras de leite longa vida (UHT) integral de quatro diferentes marcas comerciais, representadas pelas letras "A", "B", "C" e "D", sendo 30 amostras de cada marca.

As amostras foram adquiridas no comércio de Ribeirão Preto (SP) e região e analisadas no laboratório de microbiologia de alimentos do Departamento de Medicina Veterinária Preventiva da Faculdade de Ciências Agrárias e Veterinárias de Jaboticabal - UNESP.

Para a contagem padrão de microrganismos heterotróficos aeróbios ou facultativos mesófilos e termófilos viáveis, foram preparadas diluições decimais usando água peptonada a $0,1 \%$ como diluente. A seguir, $1 \mathrm{ml}$ de cada diluição $\left(10^{\circ}\right.$ a $\left.10^{-4}\right)$ foi depositado no fundo de placas de Petri esterilizadas, em quadruplicata, distribuídas em duas séries e adicionados de 15 a $17 \mathrm{ml}$ de ágar padrão para contagem fundido e resfriado à temperatura em torno de $45^{\circ} \mathrm{C}$ (Swanson et al., 1992).

Após a homogeneização e solidificação do ágar em temperatura ambiente, duas placas foram incubadas a $35^{\circ} \mathrm{C}$ por 48 horas para a contagem de microrganismos heterotróficos mesófilos e, as outras duas, a $55^{\circ} \mathrm{C}$ por 48 horas para a contagem de microrganismos heterotróficos termófilos.

As contagens foram realizadas em contador de colônias, segundo a técnica padrão, em placas com 25 a 250 UFC (unidades formadoras de colônia), e no caso de não haver placas neste intervalo, os resultados obtidos foram considerados como estimados.

A determinação de coliformes totais e fecais foi realizada através da técnica do número mais provável (NMP) (Peeler et al., 1992). O teste presuntivo foi realizado a partir do leite hidratado e das diluições decimais em água peptonada a $0,1 \%$, sendo inoculado $1 \mathrm{ml}$ de cada uma delas $\left(10^{\circ}\right.$ a $\left.10^{-2}\right)$ em três séries de três tubos de ensaio contendo caldo lauril sulfato triptose com tubo de Durhan invertido (uma série para cada diluição). Após a inoculação, os tubos foram incu- bados a $35^{\circ} \mathrm{C}$ por $24-48$ horas. Após o período, foram considerados positivos aqueles que se revelaram com a presença de crescimento bacteriano e produção de gás.

Para o teste confirmativo, de cada tubo positivo no teste presuntivo, foi transferida, com alça de níquel-cromo de $3 \mathrm{~mm}$ de diâmetro, uma alçada da cultura para tubos correspondentes contendo caldo lactose-verde brilhante-bile a $2 \%$, para pesquisa de coliformes totais, e caldo EC, para a pesquisa de coliformes fecais, todos contendo tubo de Durhan invertido. As incubações foram realizadas, respectivamente, a $35^{\circ} \mathrm{C}$ por $24-48$ horas e a $45,5 \pm 0,2^{\circ} \mathrm{C}$ por 24 horas. Foram considerados positivos os tubos que revelassem a presença de crescimento bacteriano e produção de gás.

Os resultados relativos às amostras positivas das diferentes marcas foram submetidos ao teste de hipóteses do qui-quadrado (Berquó et al., 1980)

\section{Resultados e discussão}

As Tabelas 1 e 2 apresentam os resultados das contagens de microrganismos aeróbios ou facultativos mesófilos e termófilos, respectivamente, encontrados nas amostras de leite UHT analisadas.

Pelos dados da Tabela 1 verifica-se que, das 120 amostras de leite UHT analisadas, 64 (53,3\%) apresentaram contaminação por microrganismos mesófilos, sendo $14(46,7 \%)$ da marca $A, 17(56,7 \%)$ da marca $B$, nove $(30,0 \%)$ da marca $C$ e $24(80,0 \%)$ da marca D.

Tabela 1: Distribuição das amostras de leite UHT de quatro marcas comerciais adquiridas na região de Ribeirão Preto$\mathrm{SP}$, segundo a população de microrganismos heterotróficos aeróbios ou facultativos mesófilos viáveis.

\begin{tabular}{|c|c|c|c|c|}
\hline \multirow{2}{*}{$\begin{array}{c}\text { POPULAÇÃ O } \\
\text { UFC/m I }\end{array}$} & \multicolumn{4}{|c|}{ MARCAS } \\
\hline & A & B & C & $D$ \\
\hline$<1$ & $16(53,3)^{(2)}$ & $13(43,3)$ & $21(70,0)$ & $06(20,0)$ \\
\hline $1 \mid-10^{1}$ & $06(20,0)$ & $05(16,7)$ & $07(23,4)$ & $01(3.3)$ \\
\hline $10^{1} \mid-10^{2}$ & $06(20,0)$ & $02(6,7)$ & $01(3,3)$ & - \\
\hline $10^{2} \mid-10^{3}$ & $01(3,3)$ & $03(10,0)$ & - & $03(10.0)$ \\
\hline $10^{3} \mid-10^{4}$ & $01(3,3)$ & $07(23,4)$ & $01(3,3)$ & $06(20,0)$ \\
\hline $10^{4} \mid-10^{5}$ & - & - & - & $06(20,0)$ \\
\hline$>10^{5}$ & - & - & - & $08(26,7)$ \\
\hline Total Positivo & $14(46,7)_{a^{(3)}}$ & $17(56,7)_{a}$ & $09(30,0)_{a}$ & $24(80,0)_{b}$ \\
\hline $\begin{array}{c}\text { Total } \\
\text { Analisado }\end{array}$ & $30(100,0)$ & $30(100,0)$ & $30(100,0)$ & $30(100,0)$ \\
\hline
\end{tabular}

(1) Unidades formadoras de colônia por mililitro de leite analisado (2)Porcentagem em relação ao total de amostras da marca

(3) $\mathrm{Na}$ mesma linha, valores com letras diferentes diferem entre si ao nível de $95 \%$ de probabilidade

Verifica-se, pela Tabela 2, que, para microrganismos heterotróficos termófilos, a contaminação ocorreu em 44,2\% do total de 120 amostras analisadas, sendo 53 amostras contaminadas. Foram positivas na contagem de microrganismos termófilos oito $(26,7 \%)$ amostras da marca $A$, nove $(30,0 \%)$ amostras da marca B, $15(50,0 \%)$ amostras da marca $\mathrm{C}$ e $21(70,0 \%)$ amostras da marca $D$. 
Tabela 2: Distribuição das amostras de leite UHT de quatro marcas comerciais adquiridas na região de Ribeirão Preto$\mathrm{SP}$, segundo a população de microrganismos heterotróficos aeróbios ou facultativos termófilos viáveis.

\begin{tabular}{ccccc}
\hline POPULAÇÃO & \multicolumn{5}{c}{ MARCAS } \\
\cline { 2 - 5 } UFC/mI I & A & B & C & D \\
\hline$<1$ & $22(73,3)^{(2)}$ & $21(70,0)$ & $15(50,0)$ & $09(30,0)$ \\
$1 \mid-10^{1}$ & $03(10,0)$ & $02(6,7)$ & $02(6,7)$ & $01(3,3)$ \\
$10^{1} \mid-10^{2}$ & $05(16,7)$ & $03(10,0)$ & $05(16,7)$ & $01(3,3)$ \\
$10^{2} \mid-10^{3}$ & - & $02(6,7)$ & $08(26,6)$ & $02(6,7)$ \\
$10^{3} \mid-10^{4}$ & - & $02(6,6)$ & - & $14(46,7)$ \\
$10^{4} \mid-10^{5}$ & - & - & - & $03(10,0)$ \\
\hline Total Positivo & $08(26,7)_{a}^{(3)}$ & $09(30,0)$ ac & $15(50,0)_{b c}$ & $21(70,0)_{b}$ \\
\hline Total & $30(100,0)$ & $30(100,0)$ & $30(100,0)$ & $30(100,0)$ \\
Analisado & & & & \\
\hline
\end{tabular}

(1) Unidades formadoras de colônia por mililitro de leite analisado

(2) Porcentagem em relação ao total de amostras da marca

(3) $\mathrm{Na}$ mesma linha, valores com letras diferentes diferem entre si ao nível de $95 \%$ de probabilidade

Embora o teste do qui-quadrado tenha mostrado haver diferença significativa $(p<0,05)$ entre as marcas comerciais analisadas, todas as marcas apresentaram-se positivas para a presença de microrganismos mesófilos e termófilos viáveis.

A alta população microbiana encontrada em três das quatro marcas analisadas mostra a má qualidade higiênica das amostras. Essa má qualidade pode ser devida a inúmeros fatores, como qualidade da matéria-prima (leite cru) empregada na obtenção do leite UHT, qualidade da água utilizada nos laticínios e da higienização dos equipamentos que entram em contato com o leite, conhecimento da mão-de-obra empregada quanto a noções de higiene e limpeza, processamento inadequado do leite, como subtemperaturas ou contaminação pós-tratamento térmico, entre outros.

Gillis et al. (1985) verificaram que as amostras de leite cru que apresentaram maiores populações microbianas (contagem padrão em placas e microrganismos psicrotróficos) deram

\section{Referências bibliográficas}

BECKER, H., SCHALLER, G., WIESE, W. VON, TERPLAN, G. Bacillus cereus in infant foods and dried milk products. Int J Food Microbiol, v. 23, n. 1, p. 1-15, 1994.

BERQUÓ, E.S., SOUZA, J.M.P., GOTLIEB, S.L.D. Bioestatística. São Paulo: Editora Pedagógica e Universitária, 1980.

BODYFELT F.W. Heat resistant psychrotrophs affect quality of fluid milk. Dairy Rec., v. 81, n. 3, p. 96-98, 1980.

BRASIL. Portaria n. 146, de 7 de março de 1996. Aprova os Regulamentos Técnicos de Identidade e Qualidade dos Produtos Lácteos. Diário Oficial, Brasília, DF, n. 48, p. 3977-3986, Seção 1.

BRASIL. Portaria n. 451, 19 de setembro de 1997. Regulamentos Técnicos - Princípios Gerais para o Estabelecimento de Critérios e Padrões Microbiológicos para Alimentos. Diário Oficial, Brasília, DF, n. 182, p. 21005-21012, Seção 1.

COLLINS E.B. Heat resistant psychrotrophic organisms. J. Dairy Sci., v. 64, p. 157-160, 1981. origem a leite UHT com menor tempo de vida útil; pelo desenvolvimento de "off flavors".

É extremamente preocupante a alta população de microrganismos aeróbios ou facultativos mesófilos e termófilos encontrada no leite UHT. A população máxima de microrganismos mesófilos encontrada ultrapassou $1,0 \times 10^{5} \mathrm{UFC} / \mathrm{ml}$ de leite analisado (Tabela 1$)$ em oito $(26,7 \%)$ amostras da marca D. Os dados encontrados são de grande relevância, principalmente ao comparar-se o leite UHT com os diferentes tipos de leite pasteurizado (leites tipos A, B e C) quanto ao limite máximo de população microbiana permitida em cada um dos tipos. Por exemplo, o leite tipo $\mathrm{B}$, intermediário entre os tipos $A$ e $C$, pode apresentar, quando no comércio, população mesofílica máxima de $8,0 \times 10^{4} \mathrm{UFC} / \mathrm{ml}$. Já o leite tipo $\mathrm{A}$ não pode apresentar população microbiana mesofílica superior a $2,0 \times 10^{3} \mathrm{UFC} / \mathrm{ml}$. No entanto, pelos dados da Tabela 1 , verifica-se que, das 120 amostras de leite UHT analisadas, 29 $(24,2 \%)$ amostras estariam fora dos padrões estabelecidos pelo Ministério da Saúde (Brasil, 1997), se fossem leite tipo A e $14(11,7 \%)$, se fossem leite tipo B.

Mais preocupante ainda é a análise da marca $D$ individualmente, já que, das 30 amostras analisadas, $20(66,7 \%)$ apresentaram população mesofílica superior à permitida para 0 leite tipo A e $14(46,7 \%)$ para o leite tipo B (Brasil, 1997).

Embora a única legislação interna existente sobre os padrões para o leite UHT relate apenas que "alimentos processados em embalagens herméticas, alimentos apertizados ou pasteurizados estáveis à temperatura ambiente e comercialmente estéreis: após 10 dias incubados a $35^{\circ} \mathrm{C}$ não devem existir sinais de alteração da embalagem nem quaisquer modificações físicas, químicas e organolépticas do produto que evidenciem deterioração" (Brasil, 1997), para o Mercosul é estabelecido que deve haver ausência de coliformes e contagem padrão em placas de microrganismos mesófilos de até $1,0 \times 10^{2} \mathrm{UFC} / \mathrm{ml}$ (Brasil, 1996). Através do presente estudo verifica-se que $36(30,0 \%)$ amostras dentre as 120 analisadas não atendem a este padrão internacional para microrganismos heterotróficos aeróbios ou facultativos mesófilos viáveis, dado que deve despertar preocupação às autoridades sanitárias da área.

GILLISW.T., CARTLEDGEM.F., RODRIGUEZI.R., SUAREZE.J. Effect of raw milk quality on ultra-high temperature processed milk. J. Dairy Sci., v. 68, n. 11, p. 2875-2879, 1985.

HITCHINS, A.D. et al. Coliforms: Escherichia coli and its toxins. In: American Public Health Association. Committee on microbiological methods for foods. Compedium of methods for the microbiological examination of foods. Washington: American Public Health Association, 1992. p. 325-369.

PEELER, J.T. et al. The most probable number technique. In: American Public Health Association. Committee on microbiological methods for foods. Compedium of methods for the microbiological examination of foods. Washington: American Public Health Association, 1992. p.105-120.

SWANSON, K.M.J. et al. Colony count methods. In: American Public Health Association. Committee on microbiological methods for foods. Compedium of methods for the microbiological examination of foods. Washington: American Public Health Association, 1992. p. 75-95. 